\title{
$\beta$-catenin decreases acquired TRAIL resistance in non-small-cell lung cancer cells by regulating the redistribution of death receptors
}

\author{
CHENGCHENG YOU $^{1,2^{*}}$, SHIMIN ZHANG ${ }^{1 *}$, YINGMING SUN ${ }^{1}$, SHIYU ZHANG ${ }^{1}$, GUILIANG TANG ${ }^{1}$, \\ FANG TANG ${ }^{1}$, XUEFENG LIU ${ }^{3}$, YU XIAO ${ }^{4,5}$, JUNHONG ZHANG ${ }^{1}$, YAN GONG $^{4}$ and CONGHUA XIE ${ }^{1,6,7}$ \\ ${ }^{1}$ Department of Radiation and Medical Oncology, Zhongnan Hospital of Wuhan University, Wuhan, Hubei 430070; \\ ${ }^{2}$ Department of Pathology, China Three Gorges University Medical College, Yichang, P.R. China; \\ ${ }^{3}$ Department of Pathology, Lombardi Comprehensive Cancer Center, Georgetown University Medical School, \\ Washington, DC, USA; ${ }^{4}$ Department of Biological Repositories, ${ }^{5}$ Department of Urology, \\ ${ }^{6}$ Hubei Key Laboratory of Tumor Biological Behaviors, and ${ }^{7}$ Hubei Cancer Clinical Study Center, \\ Zhongnan Hospital of Wuhan University, Wuhan, Hubei 430070, P.R. China
}

Received May 21, 2018; Accepted July 25, 2018

DOI: 10.3892/ijo.2018.4529

\begin{abstract}
Tumor necrosis factor-related apoptosis-inducing ligand (TRAIL) exhibits antitumor activity in various types of tumor cell and tumor-bearing animals. However, acquired TRAIL resistance is a common issue that restricts its clinical application. Previous studies have revealed that $\beta$-catenin is associated with TRAIL resistance in melanoma and colorectal tumors. In the present study, an acquired-resistance non-small-cell lung cancer (NSCLC) cell line (H460-TR) was established from parental TRAIL-sensitive H460 cells using a gradient ascent model (8-256 ng/ml TRAIL). Cellular FADD-like interleukin-1 $\beta$ converting enzyme inhibitory protein and Mcl-1 were upregulated and the cell surface distribution of death receptor (DR)4 and DR5 was
\end{abstract}

Correspondence to: Dr Conghua Xie, Department of Radiation and Medical Oncology, Zhongnan Hospital of Wuhan University, 169 Donghu Road, Wuhan, Hubei 430070, P.R. China

E-mail: chxie_65@whu.edu.cn

Dr Yan Gong, Department of Biological Repositories, Zhongnan Hospital of Wuhan University, 169 Donghu Road, Wuhan, Hubei 430070, P.R. China

E-mail: yan.gong@whu.edu.cn

${ }^{*}$ Contributed equally

Abbreviations: NSCLC, non-small cell lung cancer; c-FLIP, cellular FADD-like interleukin-1 $\beta$ converting enzyme inhibitory protein; DR, death receptor; DcR, decoy receptor; DISC, death inducing signaling complex; EMT, epithelial-mesenchymal transition; FADD, Fas associated death domain; BAX BCL-2 associated $\mathrm{X}$ protein; BAK, BCL-2-antagonist/killer

Key words: tumor necrosis factor-related apoptosis-inducing ligand, non-small-cell lung cancer, $\beta$-catenin, acquired resistance, death receptor downregulated in H460-TR cells compared with the parental H460 cells. The results of reverse transcription-quantitative polymerase chain reaction and western blot analysis indicated that $\mathrm{H} 460$ cells expressed increased levels of $\beta$-catenin and were more sensitive to TRAIL compared with H460-TR cells. $\beta$-catenin-knockdown in $\mathrm{H} 460$ cells decreased their sensitivity to TRAIL, while upregulation of $\beta$-catenin expression in H460-TR cells increased their sensitivity to TRAIL, increased the cell surface distribution of DRs and activated caspase-3/8. Taken together, the results of the present study suggest that $\beta$-catenin impairs acquired TRAIL resistance in NSCLC cells by promoting the redistribution of DR4 and DR5 to the cytomembrane, and inducing TRAIL-mediated cell apoptosis via caspase- $3 / 8$ activation.

\section{Introduction}

Over the past 30 years, lung cancer has had high morbidity and mortality rates worldwide, with $75 \%$ of new diagnoses being classified as non-small-cell lung cancer (NSCLC) and advanced tumors at the first visit (1). Chemotherapy and radiotherapy remain the most common treatment methods for advanced cancer (2). Tumor necrosis factor-related apoptosis-inducing ligand (TRAIL) induces apoptosis in malignant tumors and has little effect on normal cells $(3,4)$. Recombinant human TRAIL and its receptor agonists are under investigation as promising therapeutic approaches for the treatment of advanced cancer (5). There are 4 different transmembrane receptors in the TRAIL receptor/ligand system, including 2 death receptors (DR4 and DR5), 2 decoy receptors (DcR1 and DcR2), and a soluble receptor, furthermore, osteoprotegerin DRs contain a cytoplasmic death domain transducing the apoptosis signalling pathway (6). Preclinical studies have revealed that recombinant TRAIL and DR agonists inhibit tumor growth in vitro and in vivo without systemic toxicity (7-9). A percentage of tumor cells were observed to respond to TRAIL therapy, which is called primary TRAIL 
resistance, while some tumor cells obtained TRAIL resistance following repeated treatments, called acquired TRAIL resistance $(10,11)$. Increasing the existing understanding of the molecular alterations involved in acquired resistance and the cytotoxicity of TRAIL is required to further investigate its therapeutic potential.

A previous study reported that $\beta$-catenin and DRs were co-expressed in colonic tumor tissues. DR expression increased during colon carcinoma tumorigenesis, possibly due to upregulation of $\beta$-catenin expression (12). However, the mechanisms by which $\beta$-catenin regulates TRAIL resistance remain unclear in NSCLC (13). It was, therefore, hypothesized that $\beta$-catenin enhanced TRAIL sensitivity by regulating the redistribution of DR4 and DR5.

In the present study, a TRAIL-resistant H460-TR cell line was established to investigate the potential effects of $\beta$-catenin on DR redistribution and TRAIL sensitivity. Downregulation of $\beta$-catenin expression decreased the redistribution of DR4 and DR5 on the cell surface, and was associated with TRAIL resistance. While $\beta$-catenin-knockdown in $\mathrm{H} 460$ cells decreased their TRAIL sensitivity, upregulation of $\beta$-catenin expression in H460-TR cells rescued TRAIL sensitivity, increased DR distribution on the cytomembrane and activated caspase-3/8. $\beta$-catenin may be used as a biomarker to predict TRAIL sensitivity in the future. Patients exhibiting high $\beta$-catenin expression may benefit more from TRAIL treatment. Furthermore, the Wnt signaling pathway agonist may be used to promote TRAIL sensitivity during chemotherapy.

\section{Materials and methods}

Cells. The human NSCLC cell line, NCI-H460, was provided by the Type Culture Collection of the Chinese Academy of Sciences (Shanghai, China). Cells were cultured in RPMI-1640 medium supplemented with $10 \%$ (v/v) fetal bovine serum (both from HyClone; GE Healthcare Life Sciences, Logan, UT, USA), $100 \mathrm{U} / \mathrm{ml}$ penicillin and $100 \mathrm{mg} / \mathrm{ml}$ streptomycin at $37^{\circ} \mathrm{C}$ in an atmosphere containing $5 \% \mathrm{CO}_{2}$. The TRAIL-resistant H460-TR cell line was established using a gradient ascent model $(8,16,32,64,128$ and $256 \mathrm{ng} / \mathrm{ml}$ TRAIL) from parental TRAIL-sensitive H460 cells. Cells were continuously exposed to $50 \mathrm{ng} / \mathrm{ml}$ TRAIL to maintain their resistant capability.

Reagents and plasmids. TRAIL was purchased from Shanghai KaibaoPharmaceuticalCo.,Ltd.(Shanghai,China).Recombinant Wnt-3A was purchased from Peprotech, Inc. (Rocky Hill, NJ, USA). The pCMV-C-flag- $\beta$-catenin (pCMV- $\beta$-catenin) overexpression plasmid was constructed and identified in our laboratory, as previously described (14). $\beta$-catenin-silencing plasmids were purchased from Addgene, Inc. (Cambridge, MA, USA; cat. nos. 19761 pLKO.1.puro shRNA. $\beta$-catenin.1248 and 18803 pLKO.1.puro shRNA $\beta$-catenin). These will be abbreviated as shRNA1 and shRNA2, respectively.

Cell viability assay. Cell viability was assessed by cell counting kit-8 (CCK-8; Dojindo Molecular Technologies, Inc., Kumamoto,Japan).Cells were seeded in 96-well plates (Corning, Inc., Corning, NY, USA) at a density of $1 \times 10^{6}$ cells/well. When the cells reached $70-80 \%$ confluence, the experimental group was treated with the $0,10,25,50,100$ or $200 \mathrm{ng} / \mathrm{ml}$ TRAIL for $24 \mathrm{~h}$. The original medium was discarded and replaced with a basal media mixture containing $10 \%$ (v/v) CCK-8 for $1 \mathrm{~h}$. The optical density (OD) was measured at $450 \mathrm{~nm}$ using a microplate reader (Rayto Life and Analytical Sciences Co., Ltd., Guangming, China). Cell viability was calculated using the following formula: Cell viability $(\%)=(\mathrm{OD}$ value of the treated wells - OD value of the blank control wells)/(OD value of the negative control wells - OD value of the blank control wells). All assays contained 5 replicates and were repeated 3 times under the same conditions.

$R N A$ isolation, reverse transcription and RT-qPCR. Total RNA was extracted from cells with TRIzol (Thermo Fisher Scientific, Inc., Waltham, MA, USA), according to the manufacturer's protocol, and the RNA concentration was detected using a NanoDrop spectrophotometer (Thermo Fisher Scientific, Inc.). Reverse transcription was performed with the SuperScript First-Strand Synthesis system (Invitrogen; Thermo Fisher Scientific, Inc.), according to the manufacturer's protocol. The primer sequences were as follows (forward and reverse, respectively): DR4, 5'-AGAGAGAAGTCCCTGCACCA-3' and 5'-GTCACTCCAGGGCGTACAAT-3'; DR5, 5'-CACCAG GTGTGATTCAGGTG-3' and 5'-CCCCACTGTGCTTTGTA CCT-3'; DcR1, 5'-ACCAACGCTTCCAACAA-3' and 5'-AGG GCACCTGCTACACTT-3'; DcR2, 5'-CCTTCTTGCCTGCT ATG-3' and 5'-GTGGTCACTGTCTCCTCC-3'; FADD, 5'-GCGAGTCTGGAAGAATGTCG-3' and 5'-GGCTTGTCA GGGTGTTT-3'; Cellular FADD-like interleukin-1 $\beta$ converting enzyme inhibitory protein (c-FLIP), 5'-GGCTCCCCCTGCAT CACATC-3' and 5'-CGCAGTACACAGGCTCCAGA-3', and GAPDH, 5'-TGGAAGGACTCATGACCACA-3' and 5'-TCAGCTCAGGGATGACCTT-3'. The transcriptional level was determined using a SYBR Premix EX Taq II kit (Takara Bio, Inc., Otsu, Japan) and a CFX96 RT-qPCR detection system (Applied Biosystems; Thermo Fisher Scientific, Inc.), according to the manufacturer's protocol. The thermocycling conditions were as follows: $95^{\circ} \mathrm{C}$ for $30 \mathrm{sec}$, followed by 40 cycles of $95^{\circ} \mathrm{C}$ for $5 \mathrm{sec}$ and $60^{\circ} \mathrm{C}$ for $30 \mathrm{sec}$, then $95^{\circ} \mathrm{C}$ for $10 \mathrm{sec}$ and melting curve at $65-95^{\circ} \mathrm{C}$ with interval changes of $0.5^{\circ} \mathrm{C}$ every $5 \mathrm{sec}$. The $2^{-\Delta \Delta \mathrm{Cq}}$ method was used to analyze the fold-change in gene expression relative to GAPDH (15).

Flow cytometry. Cells were digested with EDTA-free trypsin (Corning, Inc.), harvested and washed twice with PBS. For apoptosis assays, cells were treated with an Annexin V-FITC/PI kit (BestBio Ltd., Shanghai, China), according to the manufacturer's protocols. A single-cell suspension was established using $400 \mu \mathrm{l}$ binding buffer and cells were stained with $5 \mu \mathrm{l}$ Annexin V-FITC for $30 \mathrm{~min}$ followed by staining with $7 \mu \mathrm{l}$ $20 \mathrm{mg} / \mathrm{ml}$ propridium iodide (PI) for $5 \mathrm{~min}$ at room temperature. To detect cytomembrane DRs, cells were suspended in $50 \mu \mathrm{l}$ PBS containing $1 \%$ goat serum at room temperature for $30 \mathrm{~min}$. Cells were washed with PBS 3 times and incubated with the primary antibodies presented in Table I overnight at $4^{\circ} \mathrm{C}$. Subsequently, cells were washed 3 times with PBS and incubated with the secondary antibodies presented in Table II at room temperature for $30 \mathrm{~min}$. Cells were then washed with PBS and suspended in $500 \mu \mathrm{l}$ PBS. Cells were also processed as described but without primary antibody treatment, as a negative control. The samples were analyzed using a flow 
Table I. List of primary antibodies used.

\begin{tabular}{|c|c|c|c|c|}
\hline Antigen & Species & Method & Dilution & Supplier (cat. no.) \\
\hline$\beta$-catenin, human & Rabbit, polyclonal & WB & $1: 1,000$ & Abcam (6302) \\
\hline GAPDH, human & Rabbit, polyclonal & WB & $1: 5,000$ & Proteintech (10494-1-AP) \\
\hline BCL-2, human & Rabbit, monoclonal & WB & $1: 2,000$ & Abcam (34124) \\
\hline BAX, human & Rabbit, monoclonal & WB & $1: 1,000$ & Proteintech (50599-2-Ig) \\
\hline Caspase-3, human & Rabbit, polyclonal & WB & $1: 1,500$ & Proteintech (19677-1-AP) \\
\hline Cleaved caspase- 3 & Rabbit, polyclonal & WB & $1: 1,000$ & CST $(9661)$ \\
\hline Caspase-8, human & Rabbit, polyclonal & WB & $1: 1,500$ & Proteintech (13423-1-AP) \\
\hline Cleaved caspase- 8 & Rabbit, monoclonal & WB & $1: 1,000$ & CST (9496) \\
\hline FADD, human & Rabbit, polyclonal & WB & $1: 1,000$ & Abcam (24533) \\
\hline C-FLIP, human & Rabbit, polyclonal & WB & $1: 1,000$ & Abcam (ab6144) \\
\hline Mcl-1, human & Rabbit, polyclonal & WB & $1: 1,000$ & Abcam (ab32087) \\
\hline DcR1, human & Rabbit, polyclonal & WB & $1: 1,000$ & Abcam (ab2087) \\
\hline DcR2, human & Rabbit, polyclonal & WB & $1: 1,000$ & Abcam (ab2019) \\
\hline DR4, human & Rabbit, monoclonal & WB & $1: 1,000$ & CST (42533) \\
\hline DR5, human & Rabbit, monoclonal & WB & $1: 1,000$ & CST (8074) \\
\hline DR4, human & Rabbit, monoclonal & IF & $1: 100$ & CST (42533) \\
\hline DR5, human & Rabbit, monoclonal & IF & $1: 50$ & CST (8074) \\
\hline DR4, human & Rabbit, monoclonal & $\mathrm{FC}$ & $1: 50$ & CST (42533) \\
\hline DR5, human & Rabbit, monoclonal & $\mathrm{FC}$ & $1: 20$ & Bioss (bs-7352R) \\
\hline Caveolin-1 & Mouse, polyclonal & IF & $1: 100$ & R\&D (MAB5736-SP) \\
\hline
\end{tabular}

IF, immunofluorescence; FC, flow cytometry; WB, western blot; BAX, BCL2 associated X, apoptosis regulator; FADD, Fas-associated death domain; C-FLIP, cellular FADD-like interleukin-1 $\beta$ converting enzyme inhibitory protein; DcR, decoy receptor; DR, death receptor; CST, Cell Signaling Technology, Inc., Danvers, MA, USA; Abcam; Abcam, Cambridge, UK; ProteinTech; ProteinTech Group, Inc., Chicago, IL, USA; R\&D, R\&D Systems, Inc., Minneapolis, MN, USA.

Table II. Secondary antibodies and DAPI stain.

\begin{tabular}{lllcl}
\hline Secondary detection system antibody & Host & Method & Dilution & Supplier (cat. no.) \\
\hline Anti-Mouse-IgG (H+L)-HRP & Goat & WB & $1: 10,000$ & Sungene (LK2001) \\
Anti-Rabbit-IgG (H+L)-HRP & Goat & WB & $1: 10,000$ & Sungene (LK2003) \\
Hoechst 33342 nucleic acid staining (DAPI) & - & IF & $1 \mu \mathrm{g} / \mathrm{ml}$ & Sigma (D8417) \\
Anti-Mouse-IgG (H+L)-Cy3 & Goat & IF, FC & $1: 100$ & Proteintech (SA00009-1) \\
Anti-Mouse-IgG (H+L)-FITC & Goat & IF, FC & $1: 100$ & Proteintech (SA00003-11) \\
Anti-Rabbit-IgG (H+L)-R-PE & Goat & IF, FC & $1: 100$ & Proteintech (SA00008-2) \\
\hline
\end{tabular}

IF, immunofluorescence; FC, flow cytometry; WB, western blot; HRP, horseradish peroxidase.

cytometer (BD Biosciences, Franklin Lakes, NJ, USA). All experiments were repeated 3 times.

Immunofluorescence. Cells were fixed with $4 \%$ paraformaldehyde (Sangon Biotech Co., Ltd., Shanghai, China) for $30 \mathrm{~min}$ and washed 3 times with PBS. Cells were blocked with normal goat serum (MultiSciences Biotech Co., Ltd., Zhejiang, Hangzhou, China) for $30 \mathrm{~min}$ at room temperature, and incubated with primary antibodies (Table I) at $4{ }^{\circ} \mathrm{C}$ overnight. Following incubation with a FITC/Cy3-conjugated secondary antibody (Table II) for $45 \mathrm{~min}$ at room temperature, the cells were washed with PBS and the slides were stained with DAPI $(1 \mu \mathrm{g} / \mathrm{ml} ; 100 \mu \mathrm{l}$; Sigma-Aldrich; Merck KGaA, Darmstadt, Germany) at room temperature for $3 \mathrm{~min}$. Images were captured with a confocal laser scanning microscope (Nikon Corporation, Tokyo, Japan).

$\beta$-catenin-knockdown in H460 cells using shRNA lentivirus. Thesense sequence of shRNA1 was5'-GTGCTATCTGTCTGCT CTA-3', and the sense sequence of the negative control (NC) shRNA was 5'-TTCTCCGAACGTGTCACGT-3'. Lentiviral pGMLV was used to construct shRNA1 (cat. no. 19761 pLKO.1.sh. $\beta$-catenin.1248). The $\mathrm{H} 460$ cells (7x105 cells/well) were infected with shRNA1 or NC lentiviruses $\left(8 \times 10^{5}\right.$ particles/well), and screened using $3 \mathrm{mg} / \mathrm{ml}$ puromycin (Sangon Biotech Co., Ltd.) for 2 weeks. $\beta$-catenin levels were subsequently measured using RT-qPCR and western blot analyses. 
$\beta$-catenin-overexpression in H460-TR cells using plasmid transfection. H460-TR cells were cultured in 6-well plates and transfected with the pCMV- $\beta$-catenin plasmid. A total of $5 \mu \mathrm{l}$ Lipofectamine ${ }^{\circledR} 2000$ (Invitrogen; Thermo Fisher Scientific, Inc.) and $10 \mu \mathrm{g}$ plasmid were added to separate 500- $\mu 1$ aliquots of OptiMEM (Gibco; Thermo Fisher Scientific, Inc.), and incubated at room temperature for $5 \mathrm{~min}$. The diluted plasmid was added to the diluted Lipofectamine ${ }^{\circledR} 2000$ at a 1:1 ratio, and the mixture was incubated at room temperature for $20 \mathrm{~min}$. When the cells reached $70-90 \%$ confluence, they were incubated with the plasmid mixture for $6 \mathrm{~h}$. RT-qPCR and western blot analyses were performed to measure the transfection efficiency. For the negative control, a pCMV-C-Tag2C-flag plasmid (pCMV) was transfected following the same protocol.

Western blot analysis. Whole cell lysates were extracted using radioimmunoprecipitation assay buffer (Beyotime Institute of Biotechnology, Haimen, China) supplemented with protease inhibitor cocktail (Sangon Biotech Co., Ltd.). Membrane DR4 and DR5 proteins were extracted using ProteoExtract ${ }^{\circledR}$ Transmembrane Protein Extraction kit (Merck KGaA, Darmstadt, Germany), according to the manufacturer's protocol. The protein content of the supernatant was detected using a bicinchoninic acid assay (Pierce; Thermo Fisher Scientific, Inc.) using bovine serum albumin as a standard. A total of $40 \mu \mathrm{g}$ protein/lane was separated by $10 \%$ SDS-PAGE. The proteins were transferred to polyvinylidene fluoride membranes, which were subsequently probed overnight at $4^{\circ} \mathrm{C}$ with the primary antibodies listed in Table I. The membranes were washed 3 times with Tris-buffered saline with Tween and incubated with the appropriate secondary antibodies (Table II) at room temperature for $90 \mathrm{~min}$. Membranes were visualized using an enhanced chemiluminescence kit and exposed using a gel imaging analyzer (both from Bio-Rad Laboratories, Inc., Hercules, CA, USA).

Statistical analysis. All experiments were repeated 3 times and the results are presented as the mean \pm standard deviation. $50 \%$ effective concentration $\left(\mathrm{EC}_{50}\right)$ values were analyzed using GraphPad Prism 5.0 (GraphPad Software, Inc., La Jolla, CA, USA) with the following equation: $\mathrm{Y}=$ minimum dose + maximum dose-minimum dose) $/ 1+10 \operatorname{LogEC} \mathrm{C}_{50}-\mathrm{X}$. Differences between 2 groups were analyzed using unpaired Student's t-tests. $\mathrm{P}<0.05$ was considered to indicate a statistically significant difference.

\section{Results}

Establishment and identification of the acquired TRAILresistant H460-TR cell line. To explore the molecular mechanism underlying acquired TRAIL-resistance, TRAIL-resistant H460-TR cells were established using H460 cells. No morphological differences were observed between H460-TR and H460 cell lines; both were polygonal, adherent and island-like. When exposed to $80 \mathrm{ng} / \mathrm{ml}$ TRAIL for $4 \mathrm{~h}$, the majority of H460 cells presented apoptotic features, while H460-TR cells maintained a typical epithelioid monolayer (Fig. 1A). The toxicity of TRAIL to H460-TR and H460 cells was assessed using CCK-8 assays and was demonstrated to be dose-dependent. The $\mathrm{EC}_{50}$ value of TRAIL in H460-TR cells was $201.4 \mathrm{ng} / \mathrm{ml}$, compared with $65.47 \mathrm{ng} / \mathrm{ml}$ in H460 cells (Fig. 1B). Furthermore, the number of Annexin V and TUNEL-positive cells decreased in the H460-TR cell line compared with the parental H460 cell line (Fig. 1C and D). These results indicate the successful establishment of an acquired TRAIL-resistant cell line.

The extrinsic and intrinsic apoptotic signaling pathways were inhibited in acquired TRAIL-resistant NSCLC cells. The effects of TRAIL on the extrinsic and intrinsic apoptotic signaling pathways in the established TRAIL-resistant H460-TR cells were investigated. No significant difference was observed in the expression of FADD or caspase- 8 protein between $\mathrm{H} 460$ and H460-TR cells; however, the mRNA and protein expression levels of c-FLIP were increased in the TRAIL-resistant cells (Fig. 2A and B). The endogenous anti-apoptotic protein, Mcl-1, was upregulated in H460-TR cells (Fig. 2C). Furthermore, the expression of cleaved caspase-3/8 was significantly decreased in H460-TR cells following $80 \mathrm{ng} / \mathrm{ml}$ TRAIL treatment (Fig. 2D). These results indicate that the extrinsic and intrinsic apoptotic signaling pathways are downregulated in cells with acquired TRAIL-resistance compared with cells without.

TRAIL-induced redistribution of DR4 and DR5 to the cytomembrane is inhibited in H460-TR cells. TRAIL-induced apoptosis was reported to be initiated by TRAIL binding to DRs. The mRNA expression of TRAIL receptors was comparable between TRAIL-sensitive and TRAIL-resistant cell lines prior to TRAIL treatment (Fig. 3A). The levels of DR4 and DR5 expression in the cytomembrane were increased in $\mathrm{H} 460$ cells following TRAIL treatment, whereas no significant difference was observed in H460-TR cells following treatment compared with pre-treatment levels (Fig. 3B and D). Furthermore, the expression of DcR1 and DcR2 was not affected by TRAIL treatment in H460 or H460-TR cells (Fig. 3E). The lack of TRAIL-induced DR redistribution may be a key factor affecting TRAIL sensitivity in H460-TR cells.

$\beta$-catenin is relevant to TRAIL sensitivity. To evaluate whether $\beta$-catenin is involved in TRAIL resistance, the expression of $\beta$-catenin was analysed using RT-qPCR and western blot analysis. $\beta$-catenin was expressed in $\mathrm{H} 460$ cells at approximately twice the level of that observed in H460-TR cells $(\mathrm{P}<0.05$; Fig. 4A and $\mathrm{B})$. These results indicate that $\beta$-catenin is positively associated with TRAIL sensitivity.

Knockdown of $\beta$-catenin reduced drug sensitivity in TRAILsensitive $H 460$ cells. shRNA was used to suppress $\beta$-catenin transcription in $\mathrm{H} 460$ cells and to investigate its effect on TRAIL sensitivity and caspase activation. $\beta$-catenin mRNA expression was reduced following infection with shRNA1 to a greater degree than with shRNA2, therefore, shRNA1 was selected for use in further experiments (Fig. 4C). Silencing of $\beta$-catenin rendered $\mathrm{H} 460$ cells less sensitive to TRAIL, as revealed by the results of a CCK-8 assay (Fig. 4D). Flow cytometry was performed to analyze the apoptosis of H460 cells following treatment with or without $80 \mathrm{ng} / \mathrm{ml}$ TRAIL for $8 \mathrm{~h}$. The results further demonstrated that $\beta$-catenin-silencing attenuates the cytotoxicity of TRAIL in H460 cells (Fig. 4E and F). The western blotting proteins bands for cleaved-caspase-3/8 were also reduced following $\beta$-catenin-silencing (Fig. 4G). 
A

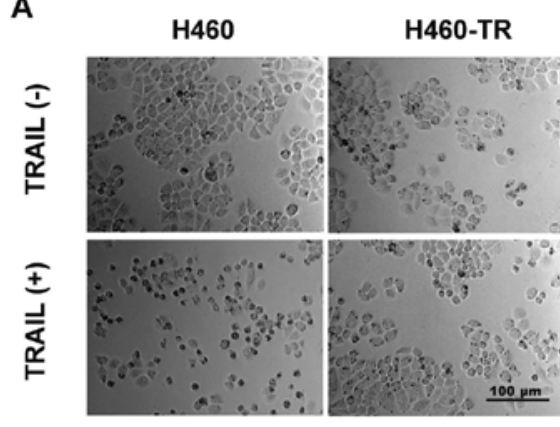

C

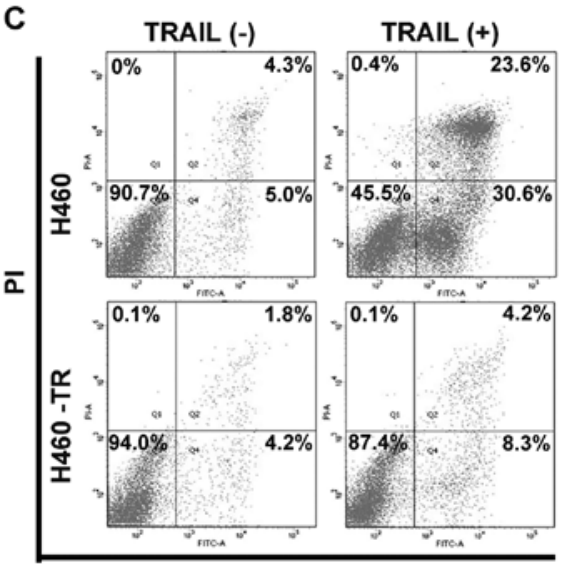

B

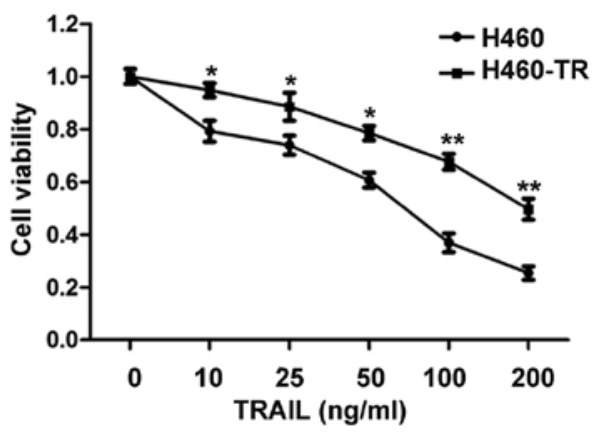

D

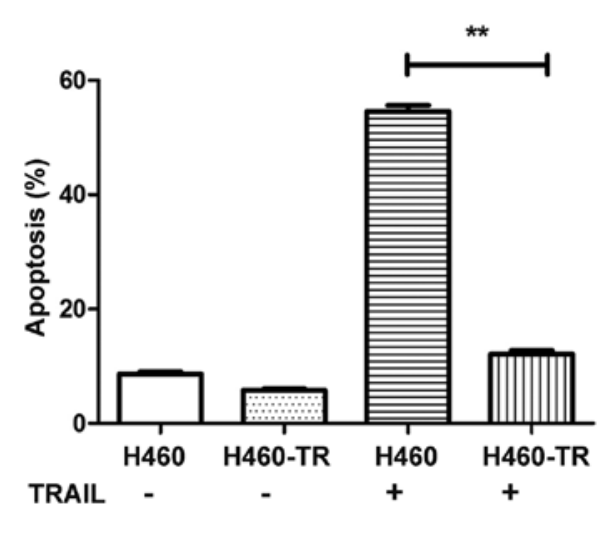

Figure 1. Establishment of TRAIL-resistant H460-TR cells and identification of TRAIL sensitivity and apoptosis. (A) Morphology of TRAIL-sensitive H460 and TRAIL-resistant H460-TR cells treated with or without $80 \mathrm{ng} / \mathrm{ml}$ TRAIL for $4 \mathrm{~h}$. Magnification, x200. Scale bar, $100 \mu \mathrm{m}$. (B) Cell viability was assessed by cell counting kit-8 assay. H460 and H460-TR cells were treated with 0-200 ng/ml TRAIL for $24 \mathrm{~h}$. (C) Flow cytometry was used to measure apoptosis of H460 and H460-TR cells exposed to $80 \mathrm{ng} / \mathrm{ml}$ TRAIL for $8 \mathrm{~h}$. (D) Quantified flow cytometry data. All assays were repeated 3 times and data are presented as the mean \pm standard deviation. ${ }^{*} \mathrm{P}<0.05$ and ${ }^{* *} \mathrm{P}<0.01$ vs. $\mathrm{H} 460$ group. TRAIL, tumor necrosis factor-related apoptosis-inducing ligand; PI, propridium iodide.

A

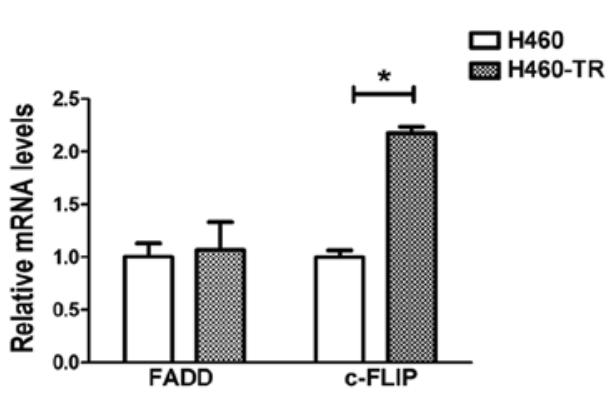

B
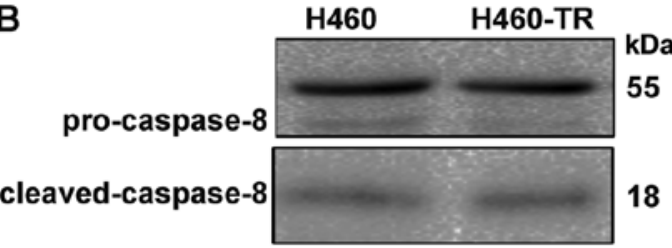

\section{FADD}
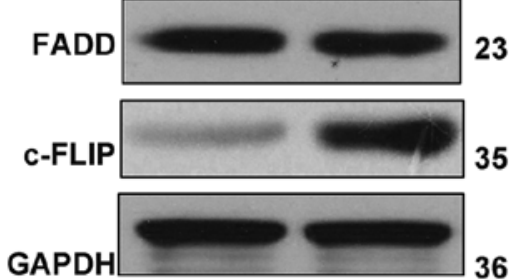

C

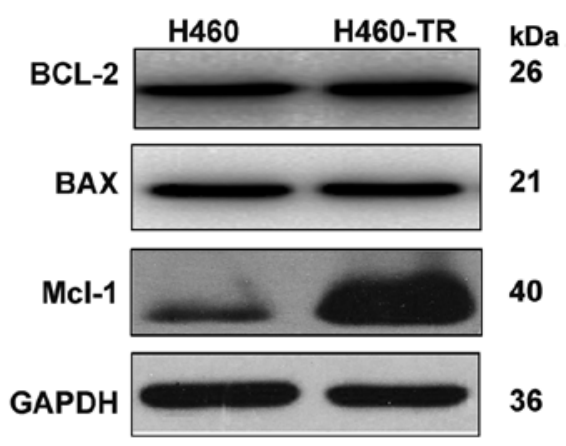

D

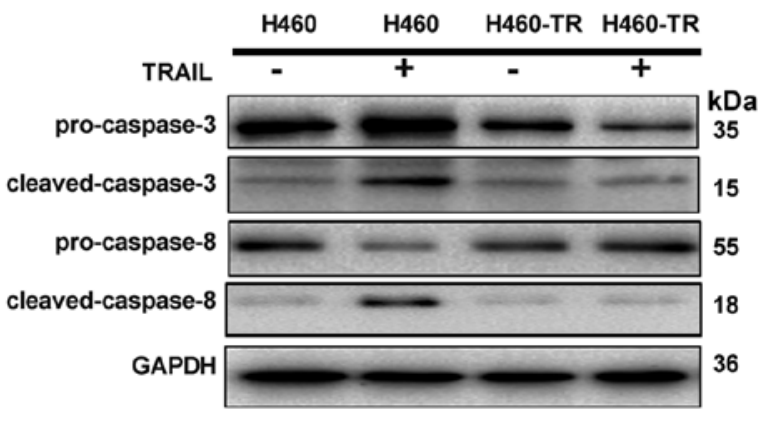

Figure 2. Expression of anti-apoptotic proteins, c-FLIP and Mcl-1, were upregulated and caspase-3/8 cleavage was downregulated in H460-TR cells following TRAIL treatment. (A) Relative expression of FADD and c-FLIP mRNA. (B) Protein expression of DISC components (FADD and caspase-8) and c-FLIP. Western blotting analysis of (C) BAX, BCL-2 and Mcl-1 and (D) caspase-3/8 protein expression. All assays were repeated 3 times and data are presented as the mean \pm standard deviation. ${ }^{*} \mathrm{P}<0.05$. C-FLIP, cellular FADD-like interleukin-1 $\beta$ converting enzyme inhibitory protein; TRAIL, tumor necrosis factor-related apoptosis-inducing ligand; PI, propridium iodide; DISC, death inducing signaling complex; FADD, Fas associated death domain; BAX, BCL-2 associated X protein. 

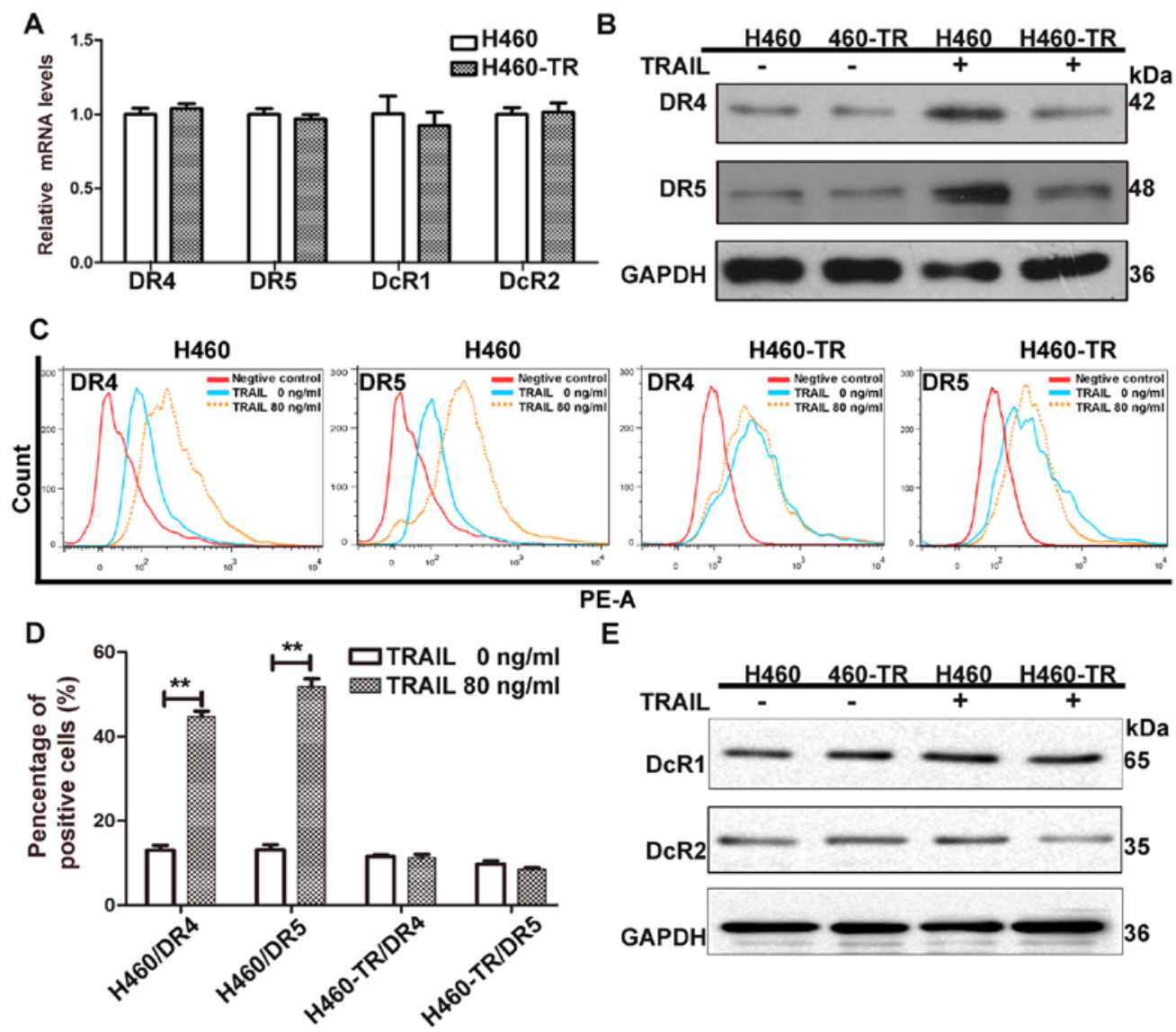

E

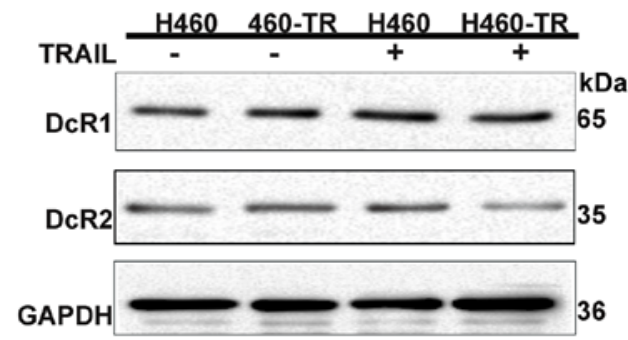

Figure 3. A lack of DR redistribution reduced H460-TR cell sensitivity to TRAIL. (A) Relative expression of TRAIL receptors was measured in H460 and H460-TR cells. (B) DR4 and DR5 protein expression was detected in H460 and H460-TR cells using western blotting. (C) Flow cytometry was used to detect cytomembranal DR4 and DR5, suggesting that TRAIL induced a lack of DR redistribution in H460-TR cells. (D) Quantified flow cytometry data. (E) The protein expression levels of TRAIL decoy receptors were detected by western blotting in H460 and H460-TR cells. All assays were repeated 3 times and data are presented as the mean \pm standard deviation. ${ }^{* *} \mathrm{P}<0.05 \mathrm{vs}$. TRAIL $0 \mathrm{ng} / \mathrm{ml}$ treatment group. DR, death receptor; DcR, decoy receptor; TRAIL, tumor necrosis factor-related apoptosis-inducing ligand.

These results indicate that $\beta$-catenin-silencing decreases TRAIL-sensitivity by inactivating caspase proteins.

Overexpression of $\beta$-catenin enhances drug sensitivity in TRAIL-resistant H460-TR cells. To further investigate the association between $\beta$-catenin expression and TRAIL sensitivity, TRAIL-resistant H460-TR cells were transfected with pCMV- $\beta$-catenin, which was successfully constructed in our previous study (14). Following transfection and puromycin screening, the expression of $\beta$-catenin protein was markedly upregulated in H460-TR cells compared with untransfected cells (Fig. 5A). The cells were next treated with TRAIL for $24 \mathrm{~h}$ and the results demonstrated that $\beta$-catenin overexpression rendered H460-TR cells more sensitive to TRAIL compared with untransfected cells (Fig. 5B). Annexin V-FITC/PI staining also indicated that $\beta$-catenin overexpression increased the apoptotic rate of H460-TR cells treated with $80 \mathrm{ng} / \mathrm{ml}$ TRAIL for $8 \mathrm{~h}$ (Fig. 5C and D) compared with untreated cells. As expected, the protein expression bands of cleaved-caspase-3/8 were larger following $\beta$-catenin overexpression (Fig. 5E). These results indicate that $\beta$-catenin overexpression increases TRAIL sensitivity via activating caspase.

$\beta$-catenin upregulates DR4 and DR5 in NSCLC cells. To determine the effects of $\beta$-catenin on DR4 and DR5 in the context of altered TRAIL sensitivity, the expression of these DRs on the cell membrane was assessed following $\beta$-catenin-silencing or overexpression. The expression of DR4 and DR5 mRNA and protein was reduced in TRAIL-sensitive H460 cells following $\beta$-catenin downregulation (Fig. 6A and B). The expression of DR4 and DR5 was increased in TRAIL-resistant H460-TR cells following $\beta$-catenin overexpression (Fig. $6 \mathrm{C}$ and D). Flow cytometry confirmed that $\beta$-catenin overexpression led to an increase in DR expression in TRAIL-resistant H460-TR cells compared with untransfected cells (Fig. 6E and F). Caveolin-1 is a marker of lipid rafts. The colocalization of Caveolin-1 and DR4/5 was assessed using immunofluorescence and confocal microscopy. The results suggest that $\beta$-catenin enhanced the localization and redistribution of DR4 and DR5 to lipid rafts (Fig. 6G). This indicates that $\beta$-catenin promotes DR translocation to the cell membrane, allowing them to combine more effectively with TRAIL and activate pro-apoptotic caspase proteins, ultimately inducing apoptosis and reversing TRAIL-resistance.

\section{Discussion}

TRAIL is able to selectively target and kill tumor cells without causing damage to normal cells $(3,4)$. DRs are often located on tumor cells and, upon activation by TRAIL, 
A

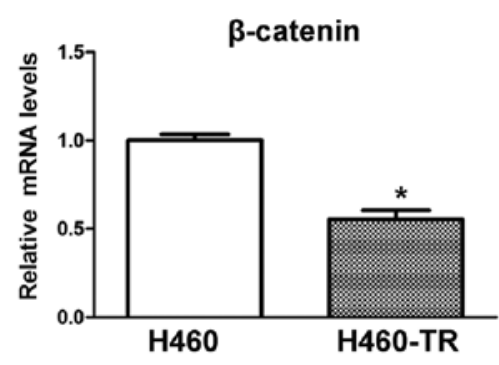

C

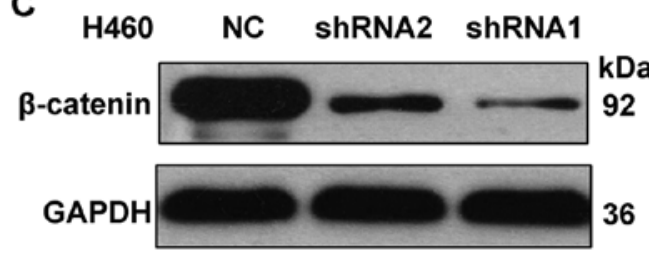

E

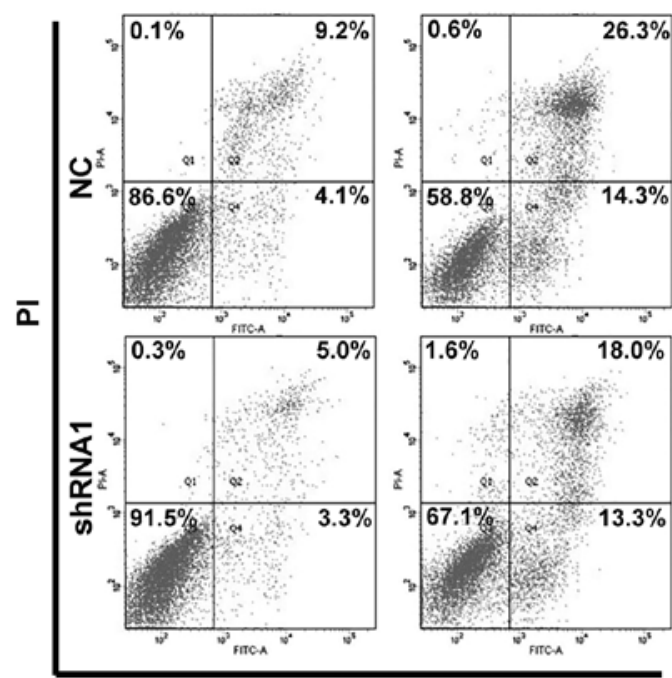

Annexin V/FITC
B

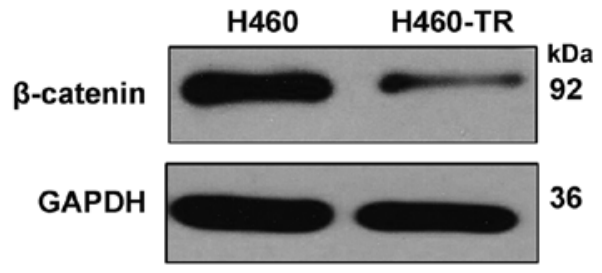

D

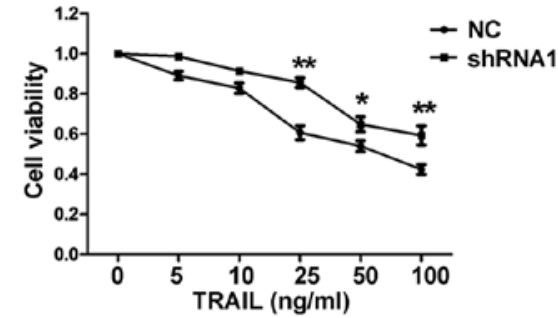

$\mathbf{F}$

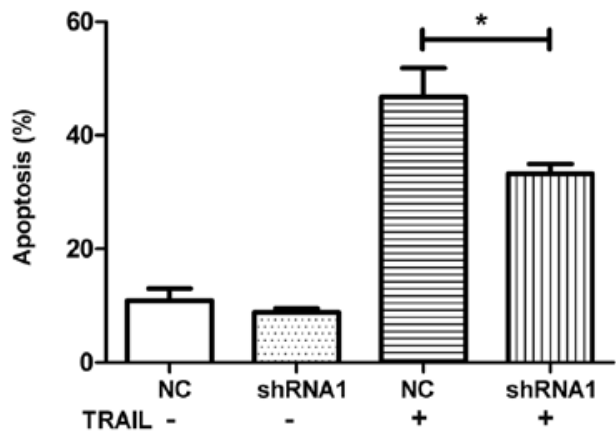

G

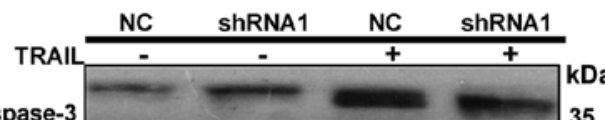

cleaved-caspase-3

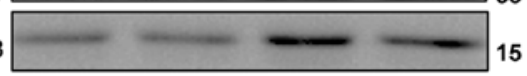

pro-caspase-8 55

cleaved-caspase-8

GAPDH

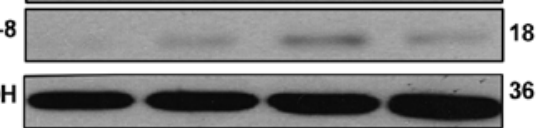

Figure 4. $\beta$-catenin-knockdown reduces drug sensitivity in TRAIL-sensitive H460 cells. (A) $\beta$-catenin mRNA expression was detected in H460 and H460-TR cells. "P<0.05 vs. $\mathrm{H} 460$ cell. (B) $\beta$-catenin protein expression was measured in $\mathrm{H} 460$ and H460-TR cells by western blot analysis. (C) Western blot analysis revealed that $\beta$-catenin expression was reduced in H460 cells treated with shRNA1 compared with negative control shRNA. (D) The viability of H460 cells

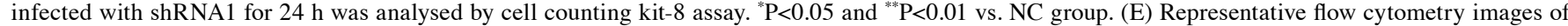
H460 cells infected with or without shRNA1 and treated with $80 \mathrm{ng} / \mathrm{ml}$ TRAIL. (F) Quantified flow cytometry data. "P $<0.05$. (G) Western blot analysis was used to measure caspase-3/8 protein expression in H460 cells with or without shRNA1 infection and $80 \mathrm{ng} / \mathrm{ml}$ TRAIL treatment. All assays were repeated 3 times and data are presented as the mean \pm standard deviation. PI, propridium iodide; NC, negative control; shRNA, short hairpin RNA; TRAIL, tumor necrosis factor-related apoptosis-inducing ligand.

the oligomerization of DRs recruits the linker molecule, Fas-associated death domain (FADD), and pro-caspase-8, which together comprise the death inducing signaling complex (DISC) (6). Activated caspase-8 directly induces apoptosis via activating caspase-3, which cleaves a broad range of apoptosis-associated protein substrates and executes the extrinsic apoptosis pathway $(16,17)$. In addition, activated caspase- 8 truncates BH3 interacting domain death agonist along with the pro-apoptotic proteins, BCL-2 associated X, apoptosis regulator and BCL-2 antagonist/killer. However, the clinical application of TRAIL is limited due to the prevalence of drug resistance $(16,17)$. TRAIL-resistance may be intrinsic, occurring at the first exposure to TRAIL, or acquired resistance, developing during treatment (18). At present, the mechanism of acquired TRAIL resistance remains to be elucidated. TRAIL resistance is caused by various factors, including endoplasmic reticulum stress (19), protein synthesis disorders (20), decreased DRs expression (21) and increased anti-apoptotic protein expression (22). Our results revealed that $\beta$-catenin expression is positively associated with TRAIL sensitivity via promoting the cytomembrane redistribution of DR4 and DR5.

c-FLIP, which is similar in structure to caspase- 8 , and competitively binds FADD molecules, thus impeding the cleavage of caspase- 8 and subsequent signal transduction in the intrinsic apoptotic signaling pathway (23). It has previously been demonstrated that TRAIL and a DR5 agonist, AD5-10, cleave c-FLIP in H460 cells (24). In human renal carcinoma Caki cells, TRAIL has been reported to downregulate c-FLIP expression and induce apoptosis (25). Mcl-1, an anti-apoptotic 
A

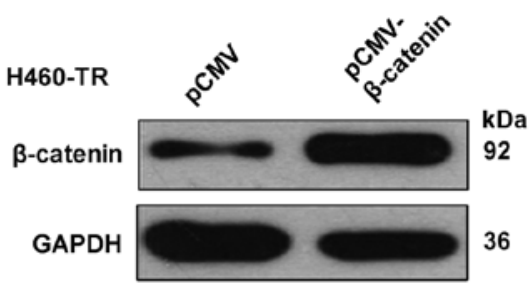

B

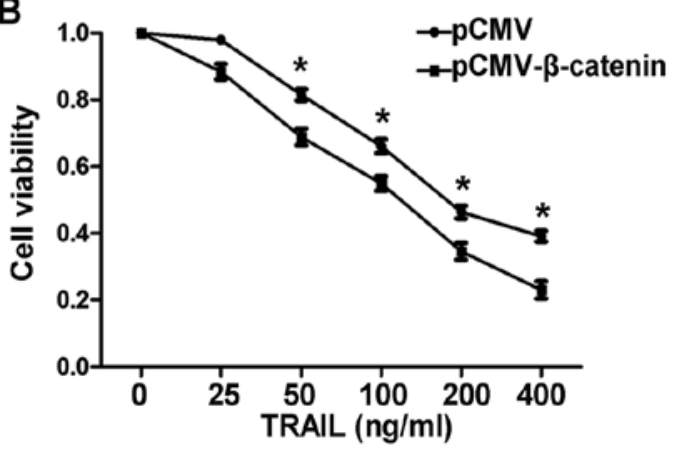

C

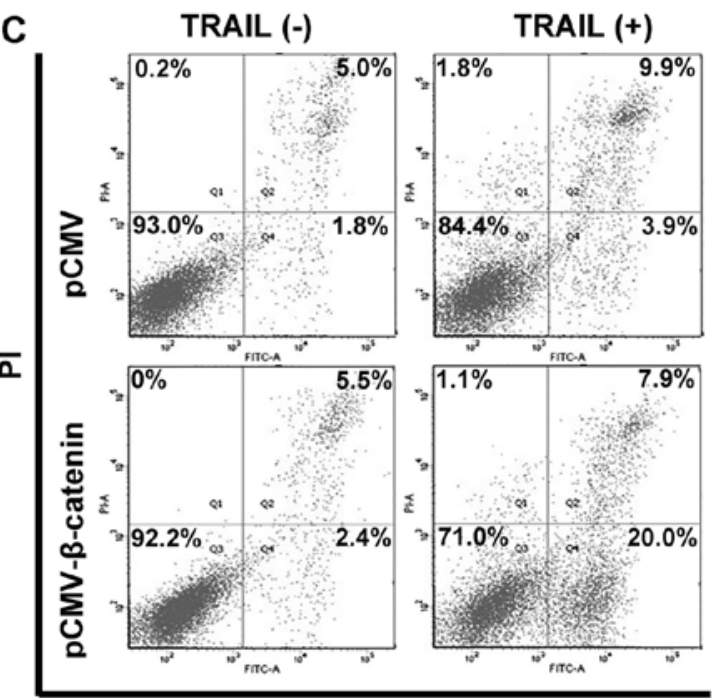

D

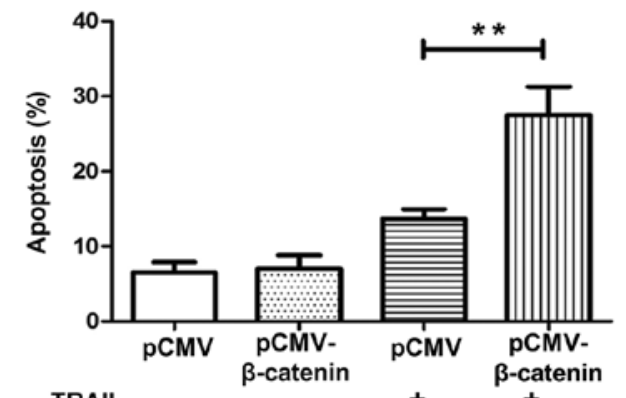

$\mathbf{E}$

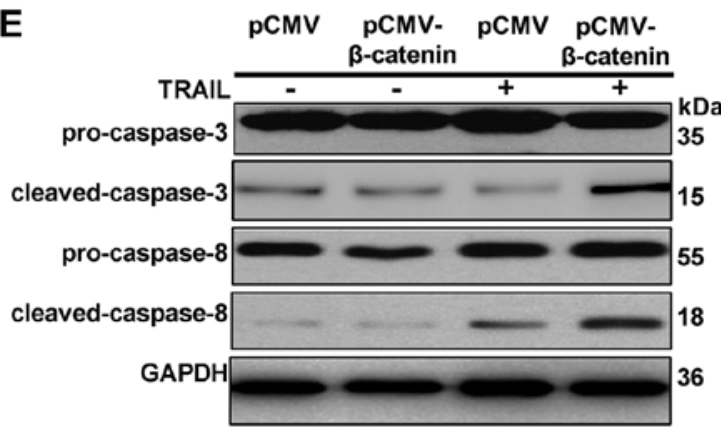

$\mathbf{F}$

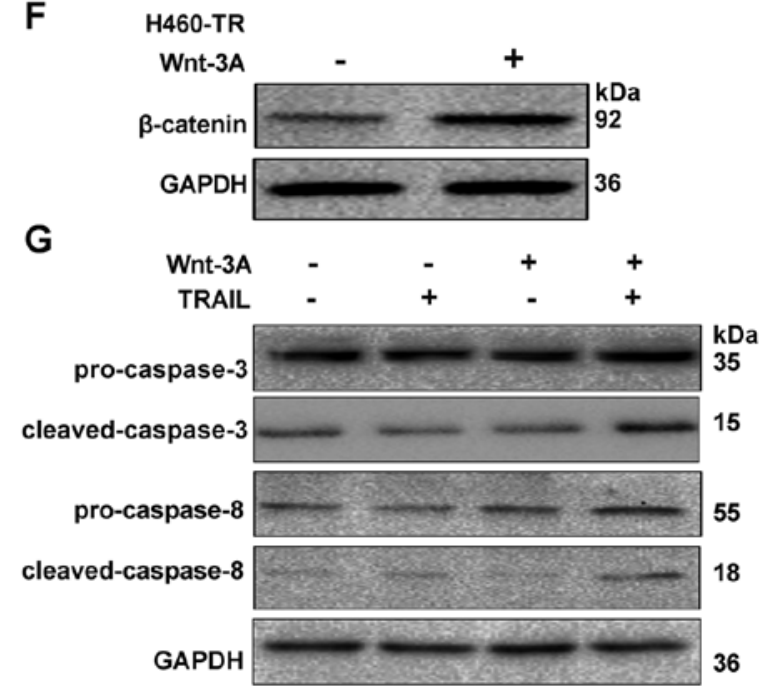

G

Figure 5. $\beta$-catenin overexpression enhances drug sensitivity in TRAIL-resistant H460-TR cells. (A) Western blot analysis revealed that $\beta$-catenin expression was upregulated in cells transfected with the pCMV- $\beta$-catenin plasmid compared with the control pCMV plasmid. (B) The viability of H460-TR cells transfected with the pCMV- $\beta$-catenin plasmid for $24 \mathrm{~h}$ was analyzed by cell counting kit- 8 assay. (C) Representative flow cytometry results of H460-TR cells transfected with or without pCMV- $\beta$-catenin plasmid and treated with $80 \mathrm{ng} / \mathrm{ml}$ TRAIL. (D) Quantified flow cytometry data. (E) Caspase-3/8 protein expression in H460-TR cells transfected with or without pCMV- $\beta$-catenin plasmid transfection and treated with $80 \mathrm{ng} / \mathrm{ml}$ TRAIL, detected using western blot analysis. (F) Wnt-3A (200 ng/ml) upregulated $\beta$-catenin expression after $48 \mathrm{~h}$. (G) Caspase-3/8 expression was analyzed using western blot analysis after treatment with $200 \mathrm{ng} / \mathrm{ml}$ Wnt- $3 \mathrm{~A}$ and $80 \mathrm{ng} / \mathrm{ml} \mathrm{TRAIL}$. All assays were repeated 3 times and data are presented as the mean \pm standard deviation. ${ }^{*} \mathrm{P}<0.05$. TRAIL, tumor necrosis factor-related apoptosis-inducing ligand.

protein that belongs to the BCL-2 family, has also been reported to induce TRAIL resistance (26). TRAIL inhibits Mcl-1 expression via activating the pro-apoptotic activity of p38 in the receptor interacting serine/threonine kinase 1-dependent pathway in $\mathrm{H} 460$ cells (27). It has also been demonstrated that YM155 sensitizes TRAIL-induced apoptosis via cathepsin S-dependent downregulation of Mcl-1 expression, and nuclear factor- $\kappa \mathrm{B}$-mediated downregulation of c-FLIP expression in Caki cells (28). In the present study, the expression of c-FLIP and Mcl-1 was higher in H460-TR cells compared with H460 cells. These results indicate that the DR-associated apoptotic pathway and the intrinsic apoptotic pathway are responsible for changes in TRAIL-sensitivity.
The binding of TRAIL to its receptors is the first step in TRAIL-induced apoptotic signaling. The cytomembrane expression of DR4 and DR5, rather than the general expression of these DRs, is the main determinant of TRAIL sensitivity (6). SW480 colon cancer cells are characterized as TRAIL-resistant cells that express high levels of DR4, even though cytomembranal DR4 is undetectable (29). The present study revealed that baseline DR4 and DR5 expression was not affected by TRAIL-sensitivity. Nevertheless, the redistribution of DR4 and DR5 to the membrane of TRAIL-sensitive H460 cells was increased following TRAIL treatment, while the cytomembranal expression levels of DR4 and DR5 in TRAIL-resistant H460-TR cells were not signifi- 

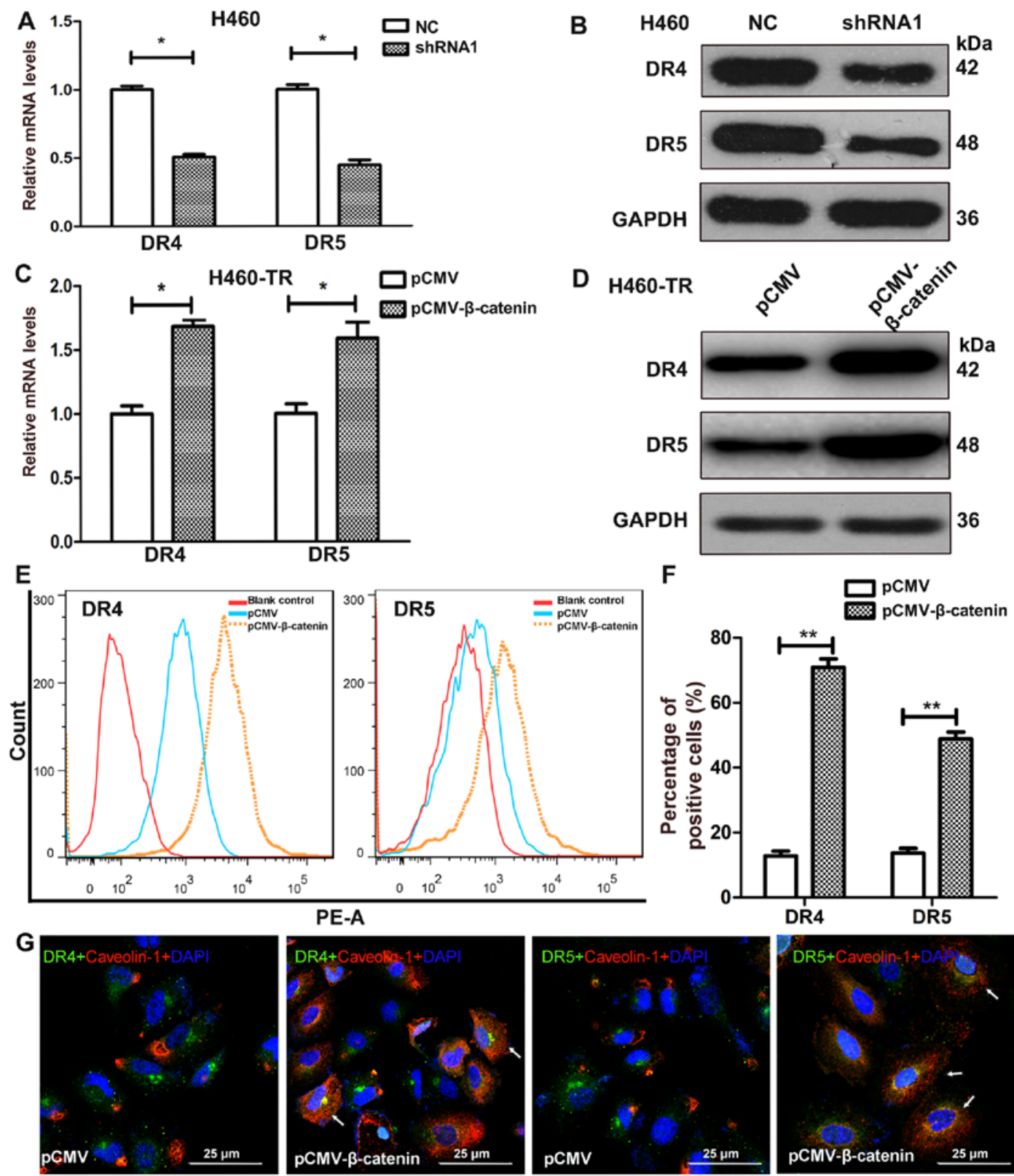

Figure 6. $\beta$-catenin upregulates DR4 and DR5 expression in NSCLC cells. DR4 and DR5 (A) mRNA and (B) protein expression in H460 cells infected with or without shRNA1 was detected. The mRNA and protein expression levels were normalized to GAPDH. DR4 and DR5 (C) mRNA and (D) protein expression levels in H460-TR cells with or without pCMV- $\beta$-catenin. (E) Cytomembranal DR4 and DR5 in H460-TR cells transfected with or without pCMV- $\beta$-catenin was assessed by flow cytometry, suggesting that $\beta$-catenin upregulated the cytomembranal expression of DR4 and DR5. (F) Quantified flow cytometry data (G) Immunofluorescence microscopy showing the localization and redistribution of DR4 and DR5 in lipid rafts induced by $\beta$-catenin overexpression. Green, red and blue areas indicate expression of DR, caveolin-1 and DAPI, respectively. Yellow areas indicate the colocalization of DR and caveolin-1 expression. Magnification, $\mathrm{x} 800$. Scale bar, $25 \mu \mathrm{m}$. All assays were repeated 3 times and data are presented as the mean \pm standard deviation. ${ }^{*} \mathrm{P}<0.05$. NC, negative control; shRNA, short hairpin RNA; DR, death receptor. TRAIL, tumor necrosis factor related apoptosis inducing ligand.

cantly altered (Fig. 3B and D). A previous study reported that TRAIL-induced DR transportation into lipid rafts in TRAIL-sensitive cells, while redistribution was not observed in TRAIL-resistant cells (30). As such, the cytomembranal expression levels of DR4 and DR5 after TRAIL treatment is critical for determining TRAIL sensitivity.

Lung cancer comprises a group of molecularly heterogeneous diseases that are characterized by a range of genomic and epigenomic alterations (31). In ongoing experiments by our research group involving a gene expression profiling chip in TRAIL-sensitive H460 cells, the acquired TRAIL-resistant H460-TR cells and the primary resistant A549 cells have demonstrated that multiple targets and genetic alternations may be associated with the resistance process (unpublished). In further experiments, it was demonstrated that $\beta$-catenin was highly expressed in TRAIL-sensitive cells compared with resistant cells. Further investigation of the association between $\beta$-catenin and TRAIL sensitivity is required.

In the canonical Wnt pathway, $\beta$-catenin accumulates in the cytoplasm upon Wnt stimulation and eventually translocates to the nucleus to act as a transcriptional coactivator (32). The Wnt/ $\beta$-catenin signaling pathway participates in cell adhesion, embryonic development and tumorigenesis (33). $\beta$-catenin and DRs are co-expressed in colonic tumor tissues. DR expression 
gradually increased during colon carcinoma tumorigenesis, possibly due to upregulation of $\beta$-catenin expression (12). In TRAIL-resistant melanoma cells, Wnt-3A was revealed to activate $\mathrm{Wnt} / \beta$-catenin signaling, promote the expression of the apoptotic molecules, BIM and PUMA, and reduce the expression of the anti-apoptotic protein, Mcl-1, thus increasing sensitivity to TRAIL (34). It was also demonstrated that Wnt-3A upregulated $\beta$-catenin expression and activated caspase- $3 / 8$ in H460-TR cells. $\beta$-catenin expression was markedly lower in cells with acquired TRAIL resistance compared with TRAIL-sensitive cells, and thus induced sensitivity to TRAIL.

While the present study demonstrated that $\beta$-catenin is a critical determinant of acquired TRAIL resistance in NSCLC cells, the exact molecular mechanisms responsible for TRAIL resistance remain unclear. $\beta$-catenin-knockdown or overexpression was used to determine whether $\beta$-catenin regulates TRAIL-sensitivity via affecting DR4 and DR5 expression. When $\beta$-catenin expression was downregulated in H460 cells, DR4 and DR5 expression levels were reduced and resistance to TRAIL increased. These results were consistent with a previous report that downregulation of $\beta$-catenin expression in melanoma cells reduced their sensitivity to TRAIL (34). Accordingly, $\beta$-catenin overexpression in H460-TR cells significantly increased DR4 and DR5 expression levels and induced TRAIL-sensitivity. Upregulation of $\beta$-catenin using lithium chloride has been reported to sensitize A549 cells to TRAIL (35). A previous study using APC-null colorectal cancer cells revealed that $\beta$-catenin upregulated c-MYC expression, which subsequently downregulated c-FLIP expression to promote TRAIL-induced apoptosis (36). It has been reported that $\mathrm{Wnt} / \beta$-catenin signalling induces apoptosis via a caspase-dependent apoptosis mechanism by downregulating expression of Mcl-1 (37). In the present study, it was revealed that $\beta$-catenin expression is positively associated with cytomembranal expression levels of DR4 and DR5, indicating that $\beta$-catenin may promote TRAIL-sensitivity by inducing the cytomembranal redistribution of DR4 and DR5.

$\beta$-catenin forms a complex with E-cadherin. Interestingly, $\beta$-catenin,E-cadherin and DR expression has been detected in the lipid rafts of the cell membrane $(38,39)$. Altering $\beta$-catenin and E-cadherin-mediated intercellular adhesion has been reported to induce epithelial-mesenchymal-transition and thus inhibit apoptosis in tumor cells (40). It was therefore speculated that the E-cadherin/ $\beta$-catenin complex enhanced cytomembranal translocation of DR4 and DR5 in $\beta$-catenin-overexpressing H460 cells. As $\beta$-catenin expression levels decline in TRAIL-resistant cells, the E-cadherin $/ \beta$-catenin complex may dissociate and the cytomembranal expression levels of DRs and DISC may be attenuated. As such, low $\beta$-catenin expression is associated with acquired TRAIL-resistance in NSCLC cells.

In the present study, an acquired TRAIL-resistant lung cancer cell line, H460-TR, was successfully constructed. It was demonstrated that the expression levels of DRs induced by TRAIL on the cell membrane is a key factor affecting acquired TRAIL resistance. TO the best of our knowledge, the present study it the first to indicate that $\beta$-catenin promotes DR-translocation to the cell membrane, allowing them to combine with TRAIL more effectively, to activate the downstream family of caspase pro-apoptotic molecules, to induce apoptosis and reverse TRAIL-resistance. In future studies, an in vivo nude mouse recombinant TRAIL xenograft model should be used to validate our in vitro results. The detailed molecular mechanisms by which $\beta$-catenin enhances TRAIL sensitivity remain to be elucidated. $\beta$-catenin overexpression or induction using Wnt-3A presents a potential therapeutic strategy to enhance TRAIL sensitivity of NSCLC cells.

\section{Acknowledgements}

The authors would like to thank Xiaohua Leng for excellent technical assistance.

\section{Funding}

The present study was funded by the Chinese National Natural Science Foundation (grant nos. 81572967, 81372498 and 81773236), Hubei Natural Science Foundation (grant no. 2013CFA006), Zhongnan Hospital of Wuhan University Science, Technology and Innovation Seed Fund (grant nos. znpy2016050 and znpy2017049), Wuhan City Huanghe Talents Plan and Chinese National Key Clinical Speciality Construction Program (CX), the Zhongnan Hospital of Wuhan University Science, Technology and Innovation Seed Fund (grant no. znpy2017001) and the Fundamental Research Funds for the Central Universities (grant no. 2042018kf0066, YG).

\section{Availability of data and materials}

All data generated or analyzed during this study were included in this published article.

\section{Authors' contributions}

CY, SHIMIN Z, YG and CX designed the present study. CY, SHIMIN Z, YS and SHIYU Z acquired the data. CY, SHIMIN Z, GT and FT analyzed the data. XL, YX and JZ interpreted the data. CY and SHIMIN Z drafted the manuscript. CY, SHIMIN Z, YG and CX provided critical revision. All authors approved the version to be published.

\section{Ethics approval and consent to participate}

Not applicable.

\section{Patient consent for publication}

Not applicable.

\section{Conflicts of interest}

The authors declare that they have no conflicts of interest.

\section{References}

1. Chen W, Zheng R, Baade PD, Zhang S, Zeng H, Bray F, Jemal A, Yu XQ and He J: Cancer statistics in China, 2015. CA Cancer J Clin 66: 115-132, 2016.

2. Cao C, D'Amico T, Demmy T, Dunning J, Gossot D, Hansen H, He J, Jheon S, Petersen RH, Sihoe A, et al; International VATS Interest Group: Surgery versus SABR for resectable non-smallcell lung cancer. Lancet Oncol 16: e370-e371, 2015. 
3. Wiley SR, Schooley K, Smolak PJ, Din WS, Huang CP, Nicholl JK, Sutherland GR, Smith TD, Rauch C, Smith CA, et al: Identification and characterization of a new member of the TNF family that induces apoptosis. Immunity 3: 673-682, 1995.

4. Hao C, Song JH, Hsi B, Lewis J, Song DK, Petruk KC, Tyrrell DL and Kneteman NM: TRAIL inhibits tumor growth but is nontoxic to human hepatocytes in chimeric mice. Cancer Res 64: 8502-8506, 2004

5. Pitti RM, Marsters SA, Ruppert S, Donahue CJ, Moore A and Ashkenazi A: Induction of apoptosis by Apo-2 ligand, a new member of the tumor necrosis factor cytokine family. J Biol Chem 271: 12687-12690, 1996

6. Ashkenazi A: Directing cancer cells to self-destruct with proapoptotic receptor agonists. Nat Rev Drug Discov 7: 1001-1012, 2008.

7. Hotte SJ, Hirte HW, Chen EX, Siu LL, Le LH, Corey A Iacobucci A, MacLean M, Lo L, Fox NL, et al: A phase 1 study of mapatumumab (fully human monoclonal antibody to TRAIL-R1) in patients with advanced solid malignancies. Clin Cancer Res 14: 3450-3455, 2008.

8. Merchant MS, Geller JI, Baird K, Chou AJ, Galli S, Charles A Amaoko M, Rhee EH, Price A, Wexler LH, et al: Phase I trial and pharmacokinetic study of lexatumumab in pediatric patients with solid tumors. J Clin Oncol 30: 4141-4147, 2012.

9. Greco FA, Bonomi P, Crawford J, Kelly K, Oh Y, Halpern W, Lo L, Gallant $\mathrm{G}$ and Klein J: Phase 2 study of mapatumumab, a fully human agonistic monoclonal antibody which targets and activates the TRAIL receptor-1, in patients with advanced non-small cell lung cancer. Lung Cancer 61: 82-90, 2008.

10. Ashkenazi A, Pai RC, Fong S, Leung S, Lawrence DA, Marsters SA, Blackie C, Chang L, McMurtrey AE, Hebert A, et al: Safty and antitumor activity of recombinant soluble Apo 2 ligand. J Clin Invest 104: 155-162, 1999.

11. Hao C, Beguinot F, Condorelli G, Trencia A, Van Meir EG, Yong VW, Parney IF, Roa WH and Petruk KC: Induction and intracellular regulation of tumor necrosis factor-related apoptosis-inducing ligand (TRAIL) mediated apotosis in human malignant glioma cells. Cancer Res 61: 1162-1170, 2001.

12. Jalving M, Heijink DM, Koornstra JJ, Boersma-van Ek W, Zwart N, Wesseling J, Sluiter WJ, de Vries EG, Kleibeuker JH and de Jong S: Regulation of TRAIL receptor expression by $\beta$-catenin in colorectal tumours. Carcinogenesis 35: 1092-1099, 2014.

13. Lu M, Marsters S, Ye X, Luis E, Gonzalez L and AshkenaziA E-cadherin couples death receptors to the cytoskeleton to regulate apoptosis. Mol Cell 54: 987-998, 2014

14. Yang B, Zhang S, Wang Z, Yang C, Ouyang W, Zhou F, Zhou Y and Xie C: Deubiquitinase USP9X deubiquitinates $\beta$-catenin and promotes high grade glioma cell growth. Oncotarget 7 : 79515-79525, 2016.

15. Livak KJ and Schmittgen TD: Analysis of relative gene expression data using real-time quantitative PCR and the 2(-Delta Delta C(T)) method. Methods 25: 402-408, 2001.

16. Rudner J, Jendrossek V, Lauber K, Daniel PT, Wesselborg S and Belka C: Type I and type II reactions in TRAIL-induced apoptosis - results from dose-response studies. Oncogene 24 130-140, 2005

17. Ozören N and El-Deiry WS: Defining characteristics of types I and II apoptotic cells in response to TRAIL. Neoplasia 4: 551-557, 2002

18. de Miguel D, Lemke J, Anel A, Walczak H and MartinezLostao L: Onto better TRAILs for cancer treatment. Cell Death Differ 23: 733-747, 2016.

19. Teng Y, Gao M, Wang J, Kong Q, Hua H, Luo T and Jiang Y: Inhibition of eIF2 $\alpha$ dephosphorylation enhances TRAIL-induced apoptosis in hepatoma cells. Cell Death Dis 5: e1060, 2014

20. Fan S, Li Y, Yue P, Khuri FR and Sun SY: The eIF4E/eIF4G interaction inhibitor 4EGI-1 augments TR AIL-mediated apoptosis through c-FLIP down-regulation and DR5 induction independent of inhibition of cap-dependent protein translation. Neoplasia 12: 346-356, 2010.

21. Haimovici A, Humbert M, Federzoni EA, Shan-Krauer D, Brunner T, Frese S, Kaufmann T, Torbett BE and Tschan MP: PU.1 supports TRAIL-induced cell death by inhibiting NF- $\kappa \mathrm{B}-$ mediated cell survival and inducing DR5 expression. Cell Death Differ 24: 866-877, 2017.
22. Mert U and Sanlioglu AD: Intracellular localization of DR5 and related regulatory pathways as a mechanism of resistance to TRAIL in cancer. Cell Mol Life Sci 74: 245-255, 2017.

23. Safa AR and Pollok KE: Targeting the anti-apoptotic protein c-FLIP for cancer therapy. Cancers (Basel) 3: 1639-1671, 2011.

24. Chen F, Guo J, Zhang Y, Zhao Y, Zhou N, Liu S, Liu Y and Zheng D: Knockdown of c-FLIP(L) enhanced AD5-10 anti-death receptor 5 monoclonal antibody-induced apoptosis in human lung cancer cells. Cancer Sci 100: 940-947, 2009.

25. Jeon MY, Min KJ, Woo SM, Seo SU,Kim S, Park JW and Kwon TK: Volasertib enhances sensitivity to TRAIL in renal carcinoma Caki cells through downregulation of c-FLIP expression. Int J Mol Sci 18: 1-12, 2017.

26. Murphy ÁC, Weyhenmeyer B, Noonan J, Kilbride SM, Schimansky S, Loh KP, Kögel D, Letai AG, Prehn JH and Murphy BM: Modulation of Mcl-1 sensitizes glioblastoma to TRAIL-induced apoptosis. Apoptosis 19: 629-642, 2014.

27. Azijli K1, Yuvaraj S, van Roosmalen I, Flach K, Giovannetti E, Peters GJ, de Jong S and Kruyt FA: MAPK p38 and JNK have opposing activities on TRAIL-induced apoptosis activation in NSCLC H460 cells that involves RIP1 and caspase- 8 and is mediated by Mcl-1. Apoptosis 18: 851-860, 2013.

28. Woo SM, Min KJ, Seo BR and Kwon TK: YM155 sensitizes TRAIL-induced apoptosis through cathepsin S-dependent downregulation of Mcl-1 and NF- $\kappa \mathrm{B}$-mediated down-regulation of c-FLIP expression in human renal carcinoma Caki cells. Oncotarget 7: 61520-61532, 2016.

29. Jin Z, McDonald ER III, Dicker DT and El-Deiry WS: Deficient tumor necrosis factor-related apoptosis-inducing ligand (TRAIL) death receptor transport to the cell surface in human colon cancer cells selected for resistance to TRAIL-induced apoptosis. J Biol Chem 279: 35829-35839, 2004.

30. Ouyang W, Yang C, Zhang S, Liu Y, Yang B, Zhang J, Zhou F, Zhou Y and Xie C: Absence of death receptor translocation into lipid rafts in acquired TRAIL-resistant NSCLC cells. Int J Oncol 42: 699-711, 2013.

31. Inamura K: Lung Cancer: Understanding its molecular pathology and the 2015 WHO classification. Front Oncol 7: 193, 2017.

32. Polakis P: Drugging Wnt signalling in cancer. EMBO J 31: 2737-2746, 2012.

33. Valenta T, Hausmann $\mathrm{G}$ and Basler K: The many faces and functions of $\beta$-catenin. EMBO J 31: 2714-2736, 2012.

34. Zimmerman ZF, Kulikauskas RM, Bomsztyk K, Moon RT and Chien AJ: Activation of Wnt/ $\beta$-catenin signaling increases apoptosis in melanoma cells treated with trail. PLoS One 8 e69593, 2013

35. Lan Y, Liu X, Zhang R, Wang K, Wang Y and Hua ZC: Lithium enhances TRAIL-induced apoptosis in human lung carcinoma A549 cells. Biometals 26: 241-254, 2013.

36. Zhang L, Ren X, Alt E, Bai X, Huang S, Xu Z, Lynch PM, Moyer MP, Wen XF and Wu X: Chemoprevention of colorectal cancer by targeting APC-deficient cells for apoptosis. Nature 464: $1058-1061,2010$

37. Wu X, Deng G, Hao X, Li Y,Zeng J, Ma C,He Y,Liu X and Wang Y: A caspase-dependent pathway is involved in Wnt/ $\beta$-catenin signaling promoted apoptosis in Bacillus Calmette-Guerin infected RAW264.7 macrophages. Int J Mol Sci 15: 5045-5062, 2014.

38. Galbiati F, Volonte D, Brown AM, Weinstein DE, Ben-Ze'ev A, Pestell RG and Lisanti MP: Caveolin-1 expression inhibits Wnt/beta-catenin/Lef-1 signaling by recruiting beta-catenin to caveolae membrane domains. J Biol Chem 275: 23368-23377, 2000.

39. Gajate $\mathrm{C}$ and Mollinedo F: Cytoskeleton-mediated death receptor and ligand concentration in lipid rafts forms apoptosis-promoting clusters in cancer chemotherapy. J Biol Chem 280: 11641-11647, 2005.

40. Brozovic A: The relationship between platinum drug resistance and epithelial-mesenchymal transition. Arch Toxicol 91: 605-619, 2017. 